\title{
Tisućljetno hrvatsko glagoljaštvo i njegovi ćirilometodski korijeni
}

\begin{abstract}
Hrvatsko je glagoljaštvo kulturna pojava koja traje više od jedanaest stoljeća te koja je osobito obilježila kulturu hrvatskoga srednjovjekovlja i ranoga novovjekovlja. Ukupni tijekovi koje nazivamo poviješću hrvatske književnosti, poviješću hrvatskoga jezika, poviješću hrvatske kulture te poviješću mnogih pojedinačnih znanstvenih disciplina ne mogu se razumjeti bez poznavanja korpusa tekstova koji su stvorili hrvatski glagoljaši i bez poznavanja njihove ukupne duhovne i materijalne djelatnosti. Korijeni te djelatnosti nalaze se u djelu Svete solunske braće, Konstantina Ćirila i Metoda, posebice u Konstantinovim stavovima da se čovjek Bogu i čovjek čovjeku najprirodnije obraća na svome jeziku te da prava ljubav prema vlastitome isključuje mržnju prema drugome i drukčijemu.
\end{abstract}

Kada je papa Ivan Pavao II. 1980. svete Ćirila i Metoda proglasio suzaštitnicima Europe, nesumnjivo je htio upozoriti da Europa ima i svoje istočno krilo. Priključio ih je svetom Benediktu, dakle onome svecu čiji su sljedbenici najviše učinili upravo za onaj dio kulture koji nazivamo zajedničkom zapadnoeuropskom baštinom. Papa je tom prilikom (31. prosinca 1980.) napisao:

„Moja je najdublja želja da - dobrotom presvete trojice $i$ zagovorom Bogorodice $i$ svih svetih - otpadne sve što razjedinjuje Crkvu, narode i zemlje, a različiti oblici predaja i kultura pridonesu uzajamnom nadopunjavanju u onom bogatstvu koje je plod složnih duša. Neka svijest o tom duhovnom bogatstvu, koje se različitim putovima namrlo u baštinu pojedinih naroda europskoga kontinenta, omogući da naši suvremenici ustraju u dužnom poštovanju opravdanih zahtjeva i prava drugih naroda i u nastojanju oko mira. Neka nipošto ne sustanu pridonositi općem boljitku sviju i raditi na sretnoj budućnosti svih ljudi na Zemlji“. ${ }^{1}$

Kada sam čuo za Papinu odluku, sjetio sam se slike koja se nalazi u đakovačkom biskupskom domu, a čiji je naziv Hadrijan II. odobrava djelo Svete Braće. Sliku je dao izraditi biskup Strossmayer, a 1862. naslikao ju je rimski slikar Nikola Consoni po uputama Biskupovim i Franje Račkoga. Na slici (ulje na platnu) nalaze se papa Hadrijan II., sveti Benedikt, sveti Ćiril i Metod te biskup Strossmayer.

IVAN PAVAO DRUGI 1980. 
Dakle, na slici koju je dao izraditi Strossmayer nalazi se poruka koja anticipira papinske odluke koje će stići više od stotinu godina kasnije. Takvi su Biskupovi vidoviti potezi mogli izaći samo iz dubokoga razumijevanja povijesti hrvatskih i bliskih krajeva.

Benediktinci su nositelji kulture latinskoga jezika, a samo su rijetko, kao u Hrvatskoj, bili i nositelji kulture drukčijega jezičnoga izraza, kao što nam to svjedoče - da spomenem samo najpoznatije - Bašćanska ploča i glagoljaška benediktinska Regula (hrvatski je prijevod, uz anglosaksonski i armenski, najstariji prijevod te regule s latinskoga na neki drugi jezik). Papine misli koje sam naveo potvrda su kako je i on djelo Solunske braće čitao kao inspiraciju da kulturne i druge različitosti prihvaćamo kao bogaćenje, kao mamac koji privlači našu znatiželju za upoznavanjem drugog i drukčijeg, da se obogatimo i tom se bogaćenju radujemo. Tako su ćirilometodsko djelo tumačili mnogi kroz povijest.

Godine 1939. u Milanu se kardinal Hermenegildo Pellegrinetti (papin poslanik u prvoj Jugoslaviji od 1922. do 1937.) našao u osjetljivom položaju: morao je govoriti u velikoj dvorani punoj fašista. Odlučio je govoriti im o Konstantinu Filozofu, tj. o svetom Ćirilu i njegovu bratu svetom Metodu te je, uz ostalo, rekao:

„Sveti je Ćiril posjedovao ono što je danas rijetkost, naime divnu ravnotežu između svijesti o jedinstvu ljudskoga roda koje se temelji na zajedništvu podrijetla $i$ otkupljenju, te između svijesti o individualnosti plemena i naroda koje proizlazi iz prirode i zato iz Boga“".

I malo dalje:

„Značajno je da su Ćiril i Metod u Moravskoj i u Rimu u bogoshužju upotrebljavali slavenski jezik. Nitko se ne bi čudio da su oni kao Grci upotrijebili grčki jezik koji se u Rimu u bogoslužju često upotrebljavao jer su ondje već stoljećima bili grčki samostani i mnogo grčkih doseljenika. Ali su ta dva velikana u latinskom Rimu, na grobu Sv. Petra, pred samim papom, slaveći bogoslužje slavenskim jezikom, izrazili veliku ideju kršćanskoga jedinstva". ${ }^{2}$

Kardinal je, govoreći o osobama iz devetoga stoljeća, govorio o osjetljivim problemima svojega vremena, što u uvjetima neslobode nije rijedak postupak ni u književnosti, ni u drugim oblicima komuniciranja. Događaji iz prošlosti mogu, naravno, biti i izmišljeni i ,stilizirani“, ali je kardinal svoj govor sazdao od provjerljivih činjenica, iako je riječ o vremenu, događajima i osobama iz vrlo daleke prošlosti, o kojima najčešće nemamo jako puno dokumenata, a za one koji su nam sačuvani ne možemo uvijek jamčiti da su vjerodostojni. No, gore

$2 \quad$ GRIVEC 1985: 51-52. 
spomenuti stavovi mogu se izvesti izravno iz onoga što su Sveta braća govorila i činila. U svojim polemikama u Hazariji Konstantin je Filozof stavu o izabranosti Abrahamovih sinova suprotstavljao stav o jednakosti Adamove djece, a na više je mjesta pokazao svoje razumijevanje odnosa općega i posebnoga. Kada su ga poticali neka kaže da je Grk, da pripada, dakle, superiornoj kulturi, on je odgovarao da je Adamov unuk. Na pitanje o svom podrijetlu odgovorio je:

„Adamov sam, naime, unuk“. ${ }^{3}$

Bio je Konstantin Ćiril ipak ponosan na svoj grčki narod i kulturu, što se vidi iz opisa susreta s ljudima iz drugoga naroda, koji su se razmetali dostignućima svoje sredine i koje Konstantin podsjeća da se hvale kao čovjek s malo vode u mijehu pred osobom koja je s mora. Njegove nam riječi pomažu da razlikujemo ponos na svoje od prezira prema drugome i drukčijemu. Takav je stav urodio time da je obrazovani Grk Konstantin Filozof postao zaštitnikom slavenskoga svijeta iz uvjerenja da su svi ljudi djeca Božja.

U životopisima Svete braće spominje se da su se oni u Veneciji sreli i polemizirali sa svećenicima koji su zastupali gledište da su samo tri jezika dostojna oltara: grčki, latinski i židovski. Neki filolozi drže da se ta rasprava nikada nije održala, nego da je riječ o Konstantinovu polemičkom spisu, za koji je njegov životopisac držao da je bolje prenijeti ga kao dramatičan događaj. To je pitanje zanimljivo za filologe i povjesničare, ali bilo ovako ili onako, najvažnije su misli koje nam se nude. Središnji je dio Konstantinova iskaza ovaj:

„Ne pada li kiša od Boga na sve jednako? Ili ne sja li sunce, također, na sve? Ne udišemo li svi isti zrak? A kako se vi ne stidite samo tri jezika priznavati, a hoćete da svi drugi narodi i plemena budu slijepi i gluhi? “4

Konstantin je njihov stav nazvao trojezičnim prokletstvom (trojezična hereza) i suprotstavio im se različitim argumentima. Navodima iz Svetoga pisma, posebice iz svetoga Pavla, pokazivao je da je njihovo gledište protivno Bibliji, a navodio im je i brojne kršćanske narode koji se u liturgiji služe svojim jezicima. Taj je njegov stav prožeo cijelo hrvatsko glagoljaštvo, u kome je tako vidljivo uvjerenje da se čovjek čovjeku i čovjek Bogu najprisnije obraća na materinskom jeziku. To je uvjerenje gradilo čvrstoću hrvatskoga glagoljaštva i pomagalo glagoljašima da dobro razlikuju ljubav prema svojim posebnim vrijednostima od zatvaranja i samoizolacije.

BRATULIĆ 1985: 51.

4 Isto: 77. 
Podsjetimo se u tom kontekstu prve tiskane hrvatske knjige, slavnoga glagoljskog Misala po zakonu rimskoga dvora. U njegovu kolofonu piše da je tiskanje dovršeno 22. pervara, dakle veljače, 1483. Toga dana Katolička crkva slavi Katedru Svetoga Petra ili, kako su glagoljaši govorili, Prjestol Svetago Petra, kojim se slavio i slavi autoritet Petrove stolice. Glagoljaši su odabrali taj datum kako bi rekli: Mi smo pravi katolici, mi samo nećemo latinski. Ili da se podsjetimo činjenice da su hrvatski glagoljaši preveli izvanredno velik broj funkcionalno različito usmjerenih tekstova s latinskoga, talijanskoga i češkoga. Dakle, njihova ljubav za vlastito nikako nije rezultirala kakvim uskogrudnim zatvaranjem - naprotiv! I kad su drugi izvori za njihovu djelatnost postali važniji i češći od ćirilometodskih, koncepcija gradnje jezika u njihovim tekstovima i bitni elementi njihove kulturne politike snažno su se naslanjali na učenje Svete solunske braće, prije svega na to da kršćanska ljubav nikoga ne isključuje. Zbog svega toga, ali i zbog mnogih drugih razloga nema nikakva smisla nijekati vezu između ćirilometodskoga djela i hrvatskoga glagoljaštva, kao što nema smisla hrvatsko glagoljaštvo svoditi samo na tu ćirilometodsku sastavnicu.

Povijesni dokumenti potvrđuju da je u Hrvatskoj glagoljskih tekstova sigurno bilo u 10. stoljeću ${ }^{5}$, iako se nijedan nije sačuvao, a od 11. do polovine 16. stoljeća glagoljica je premoćno pismo u bilježenju hrvatskoga jezika. Sve hrvatsko „najstarije“ i „prvo“ ostvareno je njome: kultni tekst Bašćanske ploče (već se uobičajilo reći „od Bašćanske ploče do danas“), najstariji hrvatski zakonik, Vinodolski (1288.), najstarija hrvatska tiskana knjiga - Misal po zakonu rimskoga dvora (1483.), najstarija hrvatska početnica (1527.) itd. Neki su hrvatskoglagoljski tekstovi najstariji slavenski predstavnici dotične teme: npr. dio legende o sv. Stilitu, apokrif Poslanica o poštovanju nedjelje, gotovo su svi među najstarijima. Osim toga, dobro je neprekidno upozoravati, za neke se najstarije hrvatske tekstove pisane ćirilicom i latinicom može pokazati da su prepisani iz još starijih glagoljskih matica. Najpoznatija latinična hrvatska inkunabula, Lekcionar Bernardina Splićanina iz 1495., ima svoje uzore u glagoljskim tekstovima. Poslije je taj lekcionar doživio svoje ćirilične i latinične, svoje kajkavske i štokavske stilizacije te njegova sudbina vrlo rječito govori o tome da je tadašnja čitateljska/slušateljska publika sva ta pisma i sve te jezične stilizacije doživljavala kao različite stilizacije svojega jezika.

PETROVIĆ 1988: 5-54. Autorica, uz ostalo, analizira one oskudne vijesti i indicije koje se mogu dovesti u vezu s počecima glagoljanja u Hrvata. Razvila je tezu ,da je prvo sjeme ćirilometodske slavenske kulture među Hrvatima mogla zasijati već sama ćirilometodska misija 863. godine prolazeći kroz bizantsku Dalmaciju na putu prema Moravskoj“ (52). Također je sklona tvrdnji da su neki učenici Svete braće nakon sloma slavenske misije našli utočište u Hrvatskoj. Neki su svećenici slavenskoga liturgijskoga jezika nakon Metodove smrti došli u Hrvatsku, a također je vrlo vjerojatno da su neki među njima u Veneciji prodavani kao robovi i da su dospjeli na bizantske posjede Kvarnera i Dalmacije. 
Korpus glagoljskih tekstova započinje s epigrafskim spomenicima. Najstariji su iz 11. stoljeća: Plominski natpis s likom ilirsko-rimskoga božanstva životinja i raslinja Silvana, kojega je kršćanska tradicija poistovjetila sa svetim Jurjem, pa se reljef našao u zidu crkve sv. Jurja u Plominu - na njemu je jedna nepotpuna rečenica (se e pişlъ s...); Valunska ploča (na otoku Cresu) s istom rečenicom na latinskom i na hrvatskom jeziku (glagoljicom), pa se doimlje kao simboličan uvod u suživot romanske i slavenske kulture na hrvatskim prostorima (têha sinz vъnukъ juna // Techa et filius eius Bratochna et Iunna nepus eius); Krčki natpis, važan zbog bilježenja imena opata koja su slavenska (Se zida majz opatı i radonê rugota, dobroslavı).

S razmeđa je stoljeća (11./12.) poznata Bašćanska ploča, koja sa svojih 13 redaka i 100 riječi prenosi i pjesnički stilizira obavijest iz samostanskoga kartulara da je hrvatski kralj Zvonimir darovao zemlju samostanu i crkvi svete Lucije u Jurandvoru kraj Baške na otoku Krku te nudi druge podatke i brojne zagonetke. Ploča je postala kultni tekst hrvatske kulture, simboličan početak povijesti hrvatske književnosti i hrvatskoga književnoga jezika, inspirirala je pjesnike i skladatelje. Iz istoga su vremena i Jurandvorski ulomci, četiri kamena ulomka koji su možda dijelovi ploče na kojoj se nastavlja tekst s Bašćanske ploče, a iz toga su razdoblja i neki epigrafski spomenici (Plastovski ulomak, Supetarski ulomak, Kninski ulomak), zanimljivi po izrazitom miješanju ćiriličnih i glagoljskih slova. ${ }^{6}$ Da nas uvijek mogu čekati iznenađenja, koja unekoliko mogu mijenjati ustaljena znanja o starini i rasprostranjenosti glagoljice, pokazuju pronalasci glagoljskih epigrafa s dubrovačkoga područja Konavoskoga glagoljičnoga natpisa ${ }^{7}$ i Hrvatskoga glagoljskoga natpisa Župe dubrovačke. ${ }^{8}$

Jedan kanonski staroslavenski tekst - Kločev glagoljaš (11. stoljeće) - kadšto se povezuje s hrvatskim prostorima i po postanku, a posve je sigurno da je do 15 . stoljeća bio kućna relikvija hrvatskih knezova Frankapana, koji su o tom kodeksu (imao je 1100 stranica, od kojih je sačuvano samo 14) mislili da je autograf svetoga Jeronima, pa su ga okovali u srebro i zlato. ${ }^{9}$ Najstarijim predstavnikom tzv. hrvatske redakcije staroslavenskoga jezika drže se Bečki listići (11./12. stoljeće), dva lista pergamene na kojima su prijelaznim tipom glagoljice ispisani misalski tekstovi. ${ }^{10}$ Sve do 14.

6 O tim i drugim glagoljskim epigrafima postoji respektabilna literatura. Temeljno je djelo za poznavanje te problematike: FUČ́IĆ 1982.

7 KAPETANIĆ I ŽAGAR 2001; ČUNČIĆ 2009.

8 ČUNČIĆ I PERKIĆ 2009.

9 Na sačuvanim stranicama (od kojih se 12 čuva u Tridentu, a 2 u Innsbrucku) nalazi se pet homilija: četiri su poznate i iz drugih staroslavenskih izvora (autori su im Ivan Zlatousti i Epifanije), a petu nazivaju Anonimnom homilijom te su ponuđeni prilično uvjerljivi dokazi da joj je autor sveti Metod.

10 Riječ je o proširenom gregorijanskom sakramentaru malih dimenzija, lako prenosivom, kojim su se služili misionari. Sadržajno su povezani s Kijevskim listićima, a ta dva spomenika povezuje i tzv. liturgija Svetoga Petra, koja se proširila po Iliriku, a nastala je prevođenjem latinske mise svetoga Grgura na grčki. 
stoljeća vrijeme je fragmenata, tj. nije nam se sačuvao nijedan cjelovit liturgijski ili neliturgijski kodeks. Svojedobno najbolji poznavatelj naše srednjovjekovne glagoljaške književnosti, Stjepan Ivšić, upozoravao je da su nam sačuvani fragmenti, dijelovi velikih zbornika (velikih i po knjižnom formatu i po broju stranica) s kojima je propao vrlo obilat sadržaj. Neki se tekstovi i u ovako fragmentarno očuvanoj tradiciji javljaju po nekoliko puta, što svjedoči o njihovoj iznimnoj popularnosti (npr. Poslanica o poštovanju nedjelje desetak puta).

Četrnaesto i petnaesto stoljeće zovu se zlatnim dobom hrvatskoga glagoljaštva. Iz toga vremena imamo sačuvano tridesetak cjelovitih brevijara, dvadesetak misala i tri psaltira te još puno fragmenata. U 13. stoljeću, točnije 1248., papa Inocent IV. dopustio je senjskom biskupu Filipu da se u obavljanju liturgijskih čina izjednači sa svojim vjernicima, tj. da može misiti i obavljati druge obrede na hrvatskostaroslavenskom jeziku iz knjiga pisanih glagoljicom, a četiri godine kasnije (1252.) dopustio je to i benediktincima u Omišlju na otoku Krku. Ta su papinska dopuštenja signali popustljivije rimske politike prema nelatinskim liturgijskim jezicima, pa je taj blaži stav dobro djelovao i na razvoj hrvatskoglagoljske tradicije. ${ }^{11}$ Dopuštenja su se poklopila sa zaživljavanjem plenarnih misala i brevijara koje je pokretljivi franjevački red raznio i po Hrvatskoj. No, nisu rijetka mišljenja da je širenje tih plenarnih brevijara i misala zapravo početak potpunoga vezivanja hrvatske glagoljske tradicije uz onu zapadnu u sadržajnom pogledu.

Liturgijski glagoljski korpus obično se dijeli na sjeverni i južni: sjevernoj bi skupini pripadali kodeksi s Kvarnerskih otoka (Krk, Cres) i iz Istre, a južnoj oni koji su nastali na zadarskom području, u Lici i Krbavi. Prilično je sigurno da se u zaleđu Zadra, oko Nina, nalazilo drugo žarište hrvatskoga glagoljaštva, da je ono slične starine kao kvarnersko i da je pred kvarnersko-istarskim područjem imalo i jednu važnu prednost, tj. glagoljaška je djelatnost na zadarskom području češće imala podršku istaknutih feudalaca. Ta dva područja povezivalo je treće, tj. krbavsko-ličko. Povezno područje (to je područje današnje Ličko-senjske županije) bilo je ono na kojem su u određenim vremenima pisani vrlo lijepi glagoljski kodeksi, nerijetko namijenjeni tradicionalnom glagoljaškom istarskokvarnerskom području. S toga je (ličkoga) područja lijepi Misal kneza Novaka iz 1368., koji se čuva u Beču. Valja upozoriti da brojni liturgijski glagoljski tekstovi nipošto nisu korisni samo za jezikoslovna proučavanja i istraživanja liturgijske tradicije, nego da nude izvanredne spoznaje kulturološke vrijednosti, govore o sredini u kojoj su nastali i sredini kojoj su namijenjeni; njihovi kalendari i inicijali te drugi slikovni prilozi značajni su svjedoci kulturnoga ambijenta u kojem su nastali i razine koju su tražili naručitelji iz naših kulturnih i duhovnih središta.

$\overline{11}$ RITTIG 1910; BOGOVIĆ 1994; DAMJANOVIĆ 1995. 
Kada je riječ o brevijarima, ne smije se zaboraviti da su oni bili svagdanja svećenička lektira, a da su svećenici u starijim razdobljima glavni i među autorima neliturgijskih tekstova te stoga ritam brevijarskih tekstova nerijetko odzvanja u neliturgijskom dijelu glagoljaškoga korpusa, što nije ni glagoljaška, ni hrvatska specifičnost. To još u većoj mjeri vrijedi za psaltirske tekstove. Naravno, u ovoj prilici možemo samo spomenuti važnije cjelovite misale i brevijare. Najstariji je među cjelovito sačuvanim misalima Illirico 4, a među časoslovima Prvi vrbnički (oba su iz prve polovine 14. stoljeća, časoslov možda čak iz 13. stoljeća). Ljepotom se ističe Hrvojev misal iz 1403./1404., koji je pisar Butko pisao po narudžbi Hrvoja Vukčića Hrvatinića, a danas se čuva u Biblioteci turskih sultana u Carigradu. Napominjemo da se osamdesetak poznatih knjižnica u svijetu diči primjercima hrvatskoglagoljskih, u pravilu liturgijskih tekstova. Još neki važniji misali: Vatikanski Illir. 4 (Omišaljski, poč. 14. stoljeća), Kopenhagenski misal (14. stoljeće), Oxfordski prvi (15./15. stoljeće), Oxfordski drugi (14./15. stoljeće), Berlinski misal (1402.), Njujorški misal (1400. - 1410.), Ročki (1420.). Neki poznatiji brevijari: Brevijar Vida Omišljanina (1396.), Beramski/Ljubljanski prvi (14. stoljeće), Beramski/Ljubljanski drugi (14. stoljeće), Pašmanski (14. stoljeće), Firentinski (14. stoljeće), Vatikanski Illir. 6 (14. stoljeće), Vrbnički drugi (14. stoljeće), Humski (1442.), Moskovski (1442./1443.), Novljanski prvi (1459.), Brevijar popa Mavra (1460.), Novljanski drugi (1495.) itd. Poznati hrvatskoglagoljski psaltiri jesu: Lobkowiczow (1359.) i Fraščićev (1463.). ${ }^{12} \mathrm{U}$ vezi s liturgijskim glagoljskim tekstovima treba spomenuti i jedan od dosega kojim se hrvatska kultura može doista ponositi: šest glagoljskih inkunabula, koje svjedoče o znatnim materijalnim i intelektualnim mogućnostima hrvatskih glagoljaša. ${ }^{13}$

U korpusu hrvatskoglagoljskih tekstova znatan je broj onih koji su i pisani s namjerom da u njima jezična funkcija djelovanja prevladava nad funkcijom priopćavanja. To su beletristički tekstovi i oni čine drugu veliku skupinu unutar hrvatskoglagoljskoga korpusa. Ti su se tekstovi najčešće nalazili u zbornicima jer

12 Literatura o hrvatskoglagoljskim liturgijskim tekstovima vrlo je opsežna, pa spominjem samo tri klasična djela hrvatske paleoslavistike: HERCIGONJA 1975; TANDARIĆ 1993; PANTELIĆ 2013.

13 Uz već spominjani Misal po zakonu rimskoga dvora (1483.), to su: Brevijar po zakonu rimskoga dvora (1491.), sačuvan samo u jednom primjerku koji se nalazi u venecijanskoj Marciani, Traktat o ispovijedi, koji uopće nije sačuvan, ali po zapisu iz Tkonskoga zbornika znamo da je knjiga otisnuta 1492., Baromićev brevijar (1493.), koji, osim časoslova, sadrži i misal i ritual, otisnut je u Veneciji, a sačuvalo nam se pet primjeraka, Senjski misal (1494.), kojim počinje raditi Senjska glagoljska tiskara (jedan primjerak u Sanktpeterburgu, jedan u Budimpešti), u kojoj je otisnuta i jedina hrvatskoglagoljska neliturgijska inkunabula Spovid općena (1496.), sačuvana u samo jednom primjerku, koji se nalazi u knjižnici franjevaca trećoredaca na Ksaveru u Zagrebu. Inkunabule su se i proučavale i pretiskivale, a pouzdane i bogate obavijesti mogu se naći u radovima A. Nazor (NAZOR 1984; Ista 1993). 
su zbornici najpopularniji tip glagoljaške rukopisne knjige od 14. do 16. stoljeća, ali živjeli su i prije i poslije toga vremena.

Iz prvoga razdoblja (koje završava krajem 14. stoljeća) spomenut ćemo samo najstariju sačuvanu zbirku pučkoga duhovnoga pjesništva, tzv. Parišku pjesmaricu. U njoj su nam sačuvane tematski i sadržajno različite pjesme: lijepa marijanska O Marija, Božja mati, božićna Bog se rodi u Vitliomi, pasionska Pjesan ot muki Hrstovi, dvije pjesme koje su se pjevale na oproštaju s mrtvacem (Bratja, brata sprovodimo, Tu mislimo, bratja, ča smo), rimovana legenda o sv. Jurju zmajoubojici, koja ujedinjuje elemente hagiografske i viteške poezije, te potresna, izrazito angažirana dvanaesteračka pjesma Svit se konča, pobuna protiv moralnoga posrtanja svećenstva itd. Zanimljivo je da je sedam od deset sačuvanih pjesama napisano u obliku osmeračkih distiha, što vjerojatno znači da osmerac u to vrijeme počinje prevladavati u hrvatskom pjesništvu.

S kraja toga razdoblja sačuvan nam je i Zbornik Gregora Borislavića iz 1375., koji nudi liturgijske i neliturgijske sadržaje; najstariji je sačuvan cjeloviti zbornik glagoljaške tradicije te najavljuje puno bolje sačuvano zborničko bogatstvo $\mathrm{s}$ kraja 14. te tijekom cijeloga 15. i 16. stoljeća: iz toga razdoblja imamo više od 20 sačuvanih cjelovitih zbornika. Neki su monotematski, tj. sadrže samo jednu vrstu tekstova. Najčešće je riječ o korizmenjacima, tj. zbirkama korizmenih propovijedi (npr. Korizmenjak iz Oporta, zatim Greblov korizmenjak itd.). Većina ih nudi raznolik i bogat sadržaj, a najzanimljiviji je i najbogatiji Petrisov zbornik iz 1468., koji na svojih 700 stranica predstavlja ,antologiju tekstova iz raznih razdoblja i izvora obilježenu iznimnom raznovrsnošću i slojevitošću sadržaja“. U njemu se nalaze tekstovi iz moralnog učenja, religiozno-propedeutički spisi, kazusi crkvenoga prava, crkveno govorništvo, rituali, legende, mirakuli, apokrifi, anegdote, dijelovi Lucidara, tj. srednjovjekovne enciklopedije, poezija, pripovijesti o Akiru. To je jedan cijeli dobro razveden sustav srednjovjekovnih književnih vrsta i doista ima pravo Eduard Hercigonja kad kaže da se čovjek mora zapitati kako su nastajali ti voluminozni kodeksi, na kakve su se biblioteke i na kakvo obrazovanje oslanjali. Već sam spomenuo da se u tim glagoljaškim zbornicima nalaze vrijedni prijevodi s latinskoga, talijanskoga i češkoga jezika, koji su znatno pomogli da književna čakavština i druge hrvatske književnojezične stilizacije razviju frazarij i rimarij, da postanu pogodno sredstvo za izražavanje svakoga sadržaja. Hrvatska srednjovjekovna književnost u tim zbornicima nudi većinu najpopularnijih tekstova europskoga Zapada i to bez velikoga vremenskoga zaostatka. U tom je kontekstu zanimljivo podsjetiti da najstariji ostaci hrvatske zborničke literature nude tekstove s europskoga Istoka, koji su u našu književnost ušli posredstvom staroslavenskih prijevoda. Tekstovi s europskoga Zapada kadšto su upravo posredstvom glagoljskih hrvatskih prijevoda našli put prema ćiriličnim slavenskim književnostima (npr. Nikodemovo evanđelje, kratka 
pasija sv. Andrije i sl.). To je posve u skladu s položajem Hrvatske, na kojem su se dodirivale kulturne i političke silnice europskoga Istoka i Zapada. ${ }^{14}$

No, i izvan zbornika nalaze se tekstovi koji privlače svojim literarnim dosezima. U tom ću kontekstu spomenuti samo Zapis popa Martinca, koji je po svojoj namjeni povijesno izvješće, ali je pop glagoljaš, opisujući krbavsku tragediju (9. rujna 1493.), vrlo spretno kombinirao starohrvatske i staroslavenske jezične osobine te se majstorski poslužio nekim pjesničkim figurama i oblikovao tekst koji je jako odmaknut od stilistički neutralnoga govora. Sve je to učinio u Drugom novljanskom brevijaru, koji je prepisivao u Grobniku, ali nije odolio osjećajima koji su ga obuzimali dok je slušao vijesti s Krbavskoga polja te nam je na praznim listovima časoslova ostavio svoje izvješće i svoje osjećaje. ${ }^{15}$

Kroatistima su iznimno važni glagoljski pravni spomenici, treći velik dio glagoljskoga korpusa jer je ono što zovemo „,ingua vernacula“, dakle narodni jezik, u pisanu praksu ušlo najranije upravo u tim, pravnim glagoljskim tekstovima. Ovdje je ponajprije riječ o čakavštini, ali i kajkavštini i štokavštini. Još je 1867. Vatroslav Jagić isticao ,... razborit način pravnog raspravljanja, krasno u narodnom duhu a opet juridičkom punoćom pripoviedanje stvari, te obilat i razgovietan jezik $k^{\star 16}$, naglašavajući da su ovi spomenici važni ne samo za pravnu hrvatsku povijest, nego i za književnu i kulturnu.

Osobine koje je Jagić isticao dobro se vide u Vinodolskom zakoniku (1288.), najstarijem hrvatskom zakonskom tekstu i, poslije Ruske pravde, najstarijoj kodifikaciji tradicionalnoga praslavenskoga običajnog prava. Spomenut ćemo i Razvod istarski notara Mikule, redigiran prije 1395., spoj dokumenata iz raznih razdoblja (s najstarijim slojem iz 1275.), sjedinjen u javnopravnu ispravu kojom se reguliraju granice između akvilejske patrijaršije, Venecije i pazinskih grofova. Tekst je napisan latinskim, njemačkim i hrvatskim jezikom, a sačuvala se samo hrvatska glagoljska verzija. S obzirom na to da se povezuje stvarnost iz različitih vremena, tekst se doima kao svojevrsna fikcija. Događa se stoga da takve pravne tekstove koji nisu pisani s namjerom da ih se prima kao književne danas doživljavamo kao književne te je lijep broj tih isprava postao predmetom ne samo povijesnojuridičkoga i povijesnojezičnoga, nego i književnopovijesnoga studija. ${ }^{17}$

14 Filološkim i poetološkim aspektima hrvatskoglagoljske beletristike posvećeni su brojni znanstveni radovi. Spominjem samo neke: KOLUMBIĆ 1969; PETROVIĆ 1972; HERCIGONJA 1975; FALIŠEVAC 1980; PETROVIĆ 2000; KAPETANOVIĆ, MALIĆ I ŠTRKALJ DESPOT 2010. Upozoravam i na izbor srednjovjekovnih proznih tekstova u dvjema knjigama, koje su se pojavile u poznatom nizu Matice hrvatske „Stoljeća hrvatske književnosti“: BADURINA STIPČEVIĆ 2013; DÜRRIGL 2013.

15 DAMJANOVIĆ 2002: 261-266.

16 JAGIĆ 1867: 126.

17 BRATULIĆ 1978. 
Znamenit je glagoljski pravni tekst prijevod Regule Svetoga Benedikta. Sačuvan nam je glagoljski prijepis iz 14. stoljeća, koji se naslanja na još starije prijepise, a najstariji je možda iz 12. stoljeća. Jezik na koji je Regula prevedena zanimljiva je mješavina hrvatskoga crkvenoslavenskoga i hrvatskoga narodnoga jezika. Riječ je o jednom od triju najstarijih prijevoda Regule s latinskoga na neki drugi jezik (uz anglosaksonski i armenski). Danas se čuva gdje je i nastala: u jedinom hrvatskom muškom benediktinskom samostanu u Ćokovcu kraj Tkona na otoku Pašmanu. Ima 60 listova (= 120 stranica), a misli se da je u punom obliku imao 70 listova.

Tek u zadnjim četirima desetljećima naši književni povjesničari ozbiljno vode računa o njima kao o spomenicima hrvatske književnosti. Od starijih istraživača samo je Jagić primijetio stilističke otklone od stereotipnoga pravnoga izričaja. Sedamdesetih godina 20. stoljeća hrvatska je književna povijest počela sve češće, u sve većem broju pravnih spomenika, otkrivati kako je praktična pravna namjena obogaćena književnojezičnom intelektualnom nadgradnjom, kako se objektivan način kazivanja zamjenjuje subjektivnim, kako se uvode opisi, dijalozi, pitanja, usklici i drugi pripovjedački gradbeni elementi koje ne bismo očekivali u pravnom tekstu; istraživači su ustanovili da na ritam i frazu utječu hrvatskostaroslavenski liturgijski tekstovi i usmena hrvatska književnost itd. U njima pisac često unosi onu za srednjovjekovnu književnost tako tipičnu binarnost, tj. opozicije život-smrt, tjelesno-duhovno, vječno-prolazno, dobro-zlo. Vrlo često ustanovit ćemo da je riječ o pravoj umjetnosti riječi. Pritom nam nikakva pretjerivanja nisu potrebna, tj. umjetnost ne treba tražiti u onim pravnim spomenicima u kojima je nema. Takvih je, uostalom, puno više, ali njihova je vrijednost u nečem drugom: svaka je od njih svjedok o životu na našim prostorima, svjedok je bogate pravne tradicije, svjedok je sposobnosti hrvatskoga jezika da omogući izražavanje svih vrijednosti hrvatske civilizacije.

Ne možemo se požaliti na zanimanje za hrvatske pravne spomenike: ono je uvijek postojalo i među pravnicima, i među povjesničarima, i među filolozima, ne samo hrvatskima. Poznato je da su inozemni istraživači znatno unaprijedili naše spoznaje o našim pravnim spomenicima i da su te spomenike prevodili na strane jezike jer su ih držali osobito zanimljivima svjedocima pravnoga uređivanja i pravnoga raspravljanja. Posve je stoga razumljivo da su u teškim trenucima naše povijesti hrvatski rodoljubi upozoravali na te spomenike i upotrebljavali ih kao sredstvo za tjeranje beznađa i utvrđivanje ponosa. Pišući 1852. o Istarskom razvodu, Ante je Starčević naglasio:

„Spomenik ovaj nije samo zato zlamenit što se iz njega vidi, da je kod naših otaca jezik hervatski bio sasvim služben, a ne samo služben nego i diplomatički-još onda kad mnogi zapadni narodi nisu ni mislili, da bi svoj na to veličanstveno mesto uzněli... on dokažuje koliki je bio kod otaca naših hervatski narodni ponos, kome kod nas ni traga neima". ${ }^{18}$

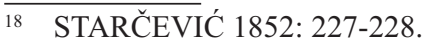


Pravni spomenici iz prošlosti poslužili su, dakle, za konstituiranje povijesne svijesti, a posebno želim naglasiti da se upravo njihovim proučavanjem smanjivala uloga mitskoga u rekonstrukciji hrvatske povijesne zbilje i da su oni svojim bogatim sadržajem poticali da se mitemi zamijene argumentima.

Za razumijevanje jezičnih rješenja na koja nailazimo u našim glagoljaškim tekstovima najprije je važno razumjeti ulogu staro(crkveno)slavenskoga. To je najstariji slavenski književni jezik nastao prevođenjem grčkih crkvenih knjiga na slavenski u 9. stoljeću. Iz toga se vremena nije sačuvao nijedan tekst, ali se za tekstove iz 10. i 11. stoljeća (staroslavenski kanon) drži da vjerno zrcale jezične osobine prvih prijevoda. Od 12. stoljeća nadalje u staroslavenske tekstove u većoj mjeri ulaze osobine živih slavenskih jezika, pa se govori o redakcijama i recenzijama staroslavenskoga jezika: češko-moravskoj, panonskoj, ruskoj, hrvatskoj, srpskoj, bugarskoj, makedonskoj i vlaškoj ili rumunjskoj.

Kad stiže na hrvatske prostore, uostalom kao i na druge, staro(crkveno)slavenski, u nekom pogledu, ima status jednak latinskom, tj. i on je nadetničko sredstvo priopćavanja, pa se u tom smislu s pravom govori o trojezičnoj (latinski-staroslavenski-hrvatski) hrvatskoj srednjovjekovnoj kulturi. Razložno se može pretpostaviti da su srednjovjekovni hrvatski čitatelji/slušatelji staroslavenski doživljavali kao stariju stilizaciju vlastitoga književnoga jezika, iako su, gledano iz nama suvremenoga jezikoslovnoga očišta, staroslavenski i starohrvatski jezični idiomi jasno odvojeni sustavi. Oni stupaju u dinamičan odnos, pa je njihovo miješanje najuočljivija osobina naših srednjovjekovnih glagoljičnih tekstova i nipošto nije lako, a kadšto uopće nije moguće jezične izraze iz tih tekstova podijeliti na staroslavenske i starohrvatske.

Već, dakle, u 9. ili najkasnije u 10. stoljeću u zemlje hrvatske vlasti stiže jezik koji mi danas zovemo staro(crkveno)slavenski, a koji se u najstarijim slavenskim tekstovima zove językı slovênbskъ. Taj termin u hrvatskoj jezičnoj tradiciji postaje jezik slovinski ili jezik slovenski ili jezik slovjenski, ovisno o tome kakav je bio refleks jata. Prevažno je razumjeti da on pokriva jezik najstarije slavenske, ćirilometodske pismenosti, u koji su sve više ulazili elementi hrvatskih mjesnih govora u to doba, vrlo sličnih tome jeziku: tako se oblikuju počeci hrvatskoga književnog jezika i taj je jezik nazivan (i) tim terminima: slov(i/e/je)nski.

Ono pak što volimo zvati „čistim hrvatskim“ najčešće ćemo naći u pravnim tekstovima. To ne treba shvatiti tako da u pravnim tekstovima uopće nema staroslavenizama; dapače, u početnim i završnim odredbama listina ima ih katkad dosta jer su pisari očito držali da njihovom uporabom stvaraju dojam svečanoga iskaza i da pokazuju kako znaju nešto što drugi ne znaju. No, u cjelini gledano, u pravnim je listinama hrvatski posve premoćan nad staroslavenskim. S obzirom na brojnost pravnih listina, na njihov prostorni i vremenski raspored, one jezi- 
koslovcima omogućuju ostvarivanje dobro razvedene slike povijesti hrvatskoga jezika, za što će, razumije se, biti nužno pod tim vidom proučiti još mnoge pravne spomenike. $^{19}$

Glagoljska će se sastavnica hrvatske pismenosti iz središta hrvatskih kulturnih događanja u 16. stoljeću pomalo seliti na periferiju i prepuštati glavnu ulogu latiničnom bilježenju hrvatskih jezičnih idioma, ali nipošto ne treba misliti da se proizvodnja glagoljskih rukopisa i tiskovina smanjila u odnosu na korpus iz „zlatnoga doba glagoljaštva“, kako volimo zvati glagoljsku pismenost 14. i 15. stoljeća. Štoviše, riječ je o znatnom korpusu, koji je hrvatska filologija istražila samo u malom dijelu, pa se o jeziku tih tekstova danas može govoriti samo u naznakama. Taj znatan korpus ne ostvaruje se na sve manjem prostoru i sa smanjenim funkcijama, kako se to u našoj filološkoj literaturi pomekad tvrdi kada se piše da je glagoljica svedena na crkvenu uporabu. Takve tvrdnje previđaju velik broj glagoljskih zbornika iz 16. stoljeća i vrlo mnogo glagoljskih tekstova administrativno-pravnoga i drugih neliturgijskih usmjerenja. Očito je da glagoljaši i dalje marljivo pišu i prepisuju, ali njihova društvena i gospodarska snaga nije dostatna za praćenje tempa koji je nametnuo izum tiska i za držanje koraka s novim snagama, koje su se i davanjem prednosti latinici u bilježenju hrvatskih idioma usklađivale sa zahtjevima novoga vremena. U jezičnom je pogledu to kadšto značilo smanjenje mogućnosti iskorištavanja rezultata šestostoljetne izgradnje, tj. kontinuitet je poremećen, iako nije i uništen. Naime, rezultati duge tradicije ugrađivali su se, barem što se leksičke, terminološke i frazeološke razine tiče, i u nove stilizacije hrvatskoga književnog jezika.

Obično se, dakle, kao kraj prirodnoga razvitka hrvatskostaroslavenskoga (hrvatskoga crkvenoslavenskoga) jezika uzima Brozićev brevijar iz 1561. Naime, poslije toga brevijara nova glagoljska knjiga bit će otisnuta tek 1631. Bio je to Levakovićev misal, otisnut u Rimu troškom Propagande nakon mnogih traženja, diplomatskih i sinodalnih intervencija. Nova je situacija uvjetovana svjetskim događajima: u Rimu je 1595. sklopljena, a u Brestu 1596. proglašena Brestovska unija, kojom su Kijev i sva Rutenija sjedinjeni s Rimom. Godine 1622. utemeljena je Congregatio de propaganda fide sa zadatkom širenja katolicizma. Snažna je želja i veliki su napori Katoličke crkve da nekako nadoknadi područja i utjecaj

19 Znanstvena je literatura o jeziku srednjovjekovnih glagoljskih tekstova uistinu bogata. Hrvatska paleoslavistička proizvodnja dugo je patila od pomanjkanja sintaktičkih i leksikoloških studija, ali je mlađi hrvatski kroatistički naraštaj tu slabost prevladao. Spominjem u ovoj prilici samo manji broj knjiga i pokoju raspravu iz druge polovine 20. i iz 21. stoljeća, u kojima se mogu naći relevantne spoznaje o jeziku hrvatskih glagoljaša: DAMJANOVIĆ 1984; HERCIGONJA 1986; VINCE 1987; MIHALJEVIĆ 1991; HERCIGONJA 1994; BABIČ 2000; ŠIMIĆ 2000; JURČEVIĆ 2002; MALIĆ 2002; VINCE 2004; MIHALJEVIĆ I REINHART 2005; MIHALJEVIĆ 2006; Isti 2007; DAMJANOVIĆ 2008; GADŽIJEVA 2013; DAMJANOVIĆ 2014; KUŠTOVIĆ 2014. 
koji su izgubljeni reformacijskim pokretom. U tim je uvjetima u Rimu velika zainteresiranost za istočnoslavenski svijet, pa je odlučeno da se napravi misal za sve katoličke Slavene koji će biti po volji Ukrajincima. Oni u tom pogledu imaju odlučujuću riječ u Rimu, pa iako je posao u oblikovanju misala povjeren hrvatskom franjevcu Rafaelu Levakoviću, „zadnja ruka“ bila je ona Metodija Terleckoga. Rusifikacija (,ukrajinizacija“) se provodila redovitim izdavanjem novih i zabranom upotrebe prijašnjih liturgijskih knjiga. Drugo izdanje svojega misala Levaković je sam priredio 1648., treće izdanje splitski kanonik Ivan Paštrić 1706. (koji nije ništa mijenjao), a četvrto Matej Karaman i Mate Sović 1741. (još radikalnije ukrajinizirano). Izrazito su ukrajinizirana i izdanja časoslova 1648. (Levaković - Terlecki) i 1688. (Paštrić). Hrvatski glagoljaši i njihovi vjernici nisu prihvaćali objašnjenja da su potrebne jedinstvene liturgijske knjige za sav katolički slavenski svijet i ta su izdanja izazvala njihovo nezadovoljstvo te, zajedno s drugim razlozima, udaljila puk od tradicije liturgijskoga slavenskog jezika. ${ }^{20}$

U Austrijskom Carstvu i Austro-Ugarskoj Monarhiji gotovo 50\% stanovništva govorilo je nekim od slavenskih jezika; tih je, dakle, govornika bilo više nego govornika njemačkoga i mađarskoga jezika zajedno. Njihov udio u strukturama državne vlasti i njihov utjecaj na ključne državne odluke nije bio ni približan njihovu udjelu u stanovništvu države. Devetnaesto stoljeće vrijeme je njihova buđenja. Jača svijest o nepravednoj podčinjenosti i traže se putovi prema boljem položaju. Mnogi ugledni Slaveni rade na jačanju slavenske uzajamnosti. Za takva nastojanja činilo im se važnim dokazivati starinu i zajedničko ishodište slavenskih kultura. U tom su se traganju nužno zaustavili na djelu Svete solunske braće Ćirila i Metoda, koji su djelovali u devetom stoljeću. Moglo se uvjerljivo dokazivati da su gotovo sve posebne slavenske srednjovjekovne književnosti naslonjene na ćirilometodsku djelatnost iz 9. stoljeća. Istraživačima iz 19. stoljeća Bilo je važno da je ta djelatnost Solunske braće bila kršćanska, da su postojali sigurni znaci njihova poštovanja papinskoga autoriteta i da su najstarije slavenske liturgijske i neliturgijske tekstove ostvarili na slavenskom liturgijskom i slavenskom književnom jeziku. Opisivati te događaje iz 9. stoljeća nije značilo samo mukotrpno skupljati podatke o davno prošlom vremenu, nego u nedostatku političke slobode govor o tim događajima ponuditi kao govor o svom vremenu, tj. o 19. stoljeću. U to stoljeće padale su velike ćirilometodske tisućite obljetnice: 1863. - tisuću godina od dolaska Solunske braće među moravske Slavene, 1869. - obljetnica Ćirilove, 1885. - Metodove smrti, a 1880. - slavila se tisućita obljetnica znamenitoga pisma pape Ivana VIII. Industriae tuae, u kome je odobrio slavenski liturgijski jezik. Te su obljetnice mobilizirale veliku energiju među katoličkim Slavenima u Monarhiji, posebno u Hrvatskoj. Tekstovi koji se o u to vrijeme objavljuju ćirilometodskoj

20 HAMM 1971; SGAMBATI 1983; BABIČ 2000. 
problematici dijelom pripadaju znanstvenim modelima, dijelom ideologemima, dijelom su, dakle, usmjereni na proučavanje, uvećavanje i produbljivanje znanja o najstarijoj slavenskoj i hrvatskoj književnojezičnoj prošlosti, dijelom na mobiliziranje u ostvarivanju političkih i društvenih ciljeva (oblikovanje moderne hrvatske nacije, slavensko jedinstvo, jedinstvo Zapadne i Istočne crkve itd.). Pokušaji da se hrvatskostaroslavenski jezik i glagoljica vrate u svakodnevni život nisu uspjeli, iako su ostavili zanimljivih i vrijednih tragova. ${ }^{21}$

Završavajući svoj nužno torzičan pogled u hrvatsko glagoljaštvo, spomenut ću još samo pismo - glagoljicu za koju s puno razloga vjerujemo da je djelo Konstantina Filozofa. ${ }^{22}$ On ju je sastavio od triju kršćanskih simbola: kruga - simbola Božje savršenosti, trokuta - simbola Presvetoga Trojstva i križa - simbola Isusove muke. Ugradio je u to pismo svoj svjetonazor, svoju filološku darovitost i obaviještenost. Sve je svoje darove ugradio u nastojanja da oplemeni drugoga uz sebe, drugoga pojedinca i drugi narod. Stoga se tako duboko, zajedno sa svojim bratom svetim Metodom, urezao u memoriju slavenskoga svijeta i zato ni jedanaest i pol stoljeća nije moglo izbrisati sjećanje na njih i poštovanje prema njihovu djelu. Uglatom inačicom toga pisma brojni su hrvatski naraštaji iskazivali darove svojega srca i uma te tim pismom uspostavili tako prisan odnos da su ga zvali, a i mi ga danas zovemo hrvatska glagoljica.

\section{Bibliografija}

BABIČ, Vanda. 2000. Vpliv vzhodne cerkvene slovanščine na hrvaške glagolske tekste v 17. in 18. stoletju. Ljubljana: Znanstveni inštitut Filozofske fakultete.

BADURINA-STIPČEVIĆ, Vesna. 1992. Hrvatskoglagoljska legenda o svetom Pavlu Pustinjaku. Zagreb: Hrvatsko filološko društvo.

BADURINA-STIPČEVIĆ, Vesna (prir.). 2013. Hrvatska srednjovjekovna proza I.: Legende i romani [Stoljeća hrvatske književnosti, knj. 115]. Zagreb: Matica hrvatska.

BOGOVIĆ, Mile. 1993. Staroslavenska liturgija u biskupijama Senjskoj i Modruškoj u 19. stoljeću i Parčićev misal. Zadarska smotra 3: 63-77.

BOGOVIĆ, Mile. 1994. Glagoljica u Senju. Senj: Jadranska tiskara d. o. o.

BRATULIĆ, Josip. 1978. Istarski razvod. Studija i tekst. Pula: Čakavski sabor.

BRATULIĆ, Josip. 1985. Žitja Konstantina Ćirila i Metodija i druga vrela. Zagreb: Kršćanska sadašnjost.

BRATULIĆ, Josip. 1988. Vinodolski zakon (faksimil, diplomatičko izdanje, kritički tekst, rječnik). Zagreb: Globus.

21 DARTEL 1984; PETROVIĆ 1985; BOGOVIĆ 1993; LUKIĆ 2009; Ista 2010; DAMJANOVIĆ 2011.

22

ŽAGAR 2013. 
CORIN, Andrew R. 2009. Variation and Norm in Croatian Church Slavonic. Slovo 4143: 155-196.

ČUNČIĆ, Marica. 2009. Novo čitanje hrvatskoga glagoljskoga Konavoskoga natpisa iz 11. stoljeća. Slovo 59: 123-133.

ČUNČIĆ, Marica, Marta PERKIĆ. 2009. Hrvatski glagoljski natpis Župe dubrovačke iz 11. stoljeća. Slovo 59: 77-122.

DAMJANOVIĆ, Stjepan. 1984. Tragom jezika hrvatskih glagoljaša. Zagreb: Hrvatsko filološko društvo.

DAMJANOVIĆ, Stjepan. 1995. Otpis pape Inocenta IV. senjskom biskupu Filipu iz godine 1248. U Jazik otačaski, 82-89. Zagreb: Matica hrvatska.

DAMJANOVIĆ, Stjepan. ${ }^{12002 .}{ }^{2} 2004 .{ }^{3} 2012$. Slovo iskona. Staroslavenska/starohrvatska čitanka. Zagreb: Matica hrvatska.

DAMJANOVIĆ, Stjepan. 2008. Jezik hrvatskih glagoljaša. Zagreb: Matica hrvatska.

DAMJANOVIĆ, Stjepan. 2011. Prošlost u sadašnjosti: Sveta Braća, Strossmayer i mi. Anali Zavoda za znanstveni rad HAZU u Osijeku 27: 17-30.

DAMJANOVIĆ, Stjepan. 2014. Novi filološki prinosi. Zagreb: Matica hrvatska.

DARTEL, Geert van. 1984. Ćirilometodska ideja i svetosavlje. Zagreb: Kršćanska sadašnjost.

DEKOVIĆ, Darko. 2005. Zapisnik misni kaptola riečkoga. Rijeka: Matica hrvatska Ogranak u Rijeci.

DÜRRIGL, Marija-Ana (prir.). 2013. Hrvatska srednjovjekovna proza II.: Apokrifi, vizije, prenja, Marijini mirakuli. Zagreb: Matica hrvatska [Stoljeća hrvatske književnosti, knj. 116].

FALIŠEVAC, Dunja. 1980. Hrvatska srednjovjekovna proza. Zagreb: Hrvatsko filološko društvo.

FUČIĆ, Branko. 1982. Glagoljica na natpisima u Bosni i Hercegovini. Nova et vetera 1-2: 255-267.

FUČIĆ, Branko. 1982. Glagoljski natpisi [Djela JAZU 57]. Zagreb: Jugoslavenska akademija znanosti i umjetnosti.

FUĆAK, Jerko. 1975. Šest stoljeća hrvatskoga lekcionara. Zagreb: Kršćanska sadašnjost.

GADŽIJEVA, Sofija. 2013. Morfonologija prezentske paradigme u hrvatskome crkvenoslavenskom jeziku. Zagreb: Hrvatska sveučilišna nastava.

GRABAR, Biserka. 1967. Apokrifna Djela apostolska u hrvatskoglagoljskoj literaturi. Radovi Staroslavenskog instituta 6: 109-208.

GRIVEC, Franc. 1985. Sveti Ćiril i Metod slavenski blagovjesnici. Prev. Livija Kirn i Vicencija Nosić. Zagreb: Kršćanska sadašnjost.

HAMM, Josip. 1952. Datiranje glagoljskih tekstova. Radovi Staroslavenskog instituta 1: $1-72$.

HAMM, Josip. 1957. Staroslavenski prijevod „Pjesme nad pjesmama“. Slovo 6-8: 195-235.

HAMM, Josip. 1963. Hrvatski tip crkvenoslavenskog jezika. Slovo 13: 43-67.

HAMM, Josip. 1965. Glagolizam i njegovo značenje za Južne Slavene. Slavia XXV: 313-321. 
HERCIGONJA, Eduard. 1975. Srednjovjekovna književnost [Povijest hrvatske književnosti 2]. Zagreb: SN Liber, Mladost.

HERCIGONJA, Eduard. 1986. Nad iskonom hrvatske knjige. Rasprave o hrvatskoglagoljskom srednjovjekovlju. Zagreb: SN Liber.

HERCIGONJA, Eduard. ${ }^{1}$ 1994. ${ }^{2} 2006$. Trojezična i tropismena kultura hrvatskoga srednjovjekovlja. Zagreb: Matica hrvatska.

HERCIGONJA, Eduard. 2004. Na temeljima hrvatske književne kulture. Zagreb: Matica hrvatska.

HERCIGONJA, Eduard. 2009. Tisućljeće hrvatskoga glagoljaštva. Zagreb: Hrvatska sveučilišna naklada.

IVAN PAVAO DRUGI (papa). 1980. Apostolsko pismo „Egregiae virtutis“ (Izvrsni kreposnici) od 31. prosinca 1980. Prev. Bonaventura Duda. Zagreb: Kršćanska sadašnjost.

IVŠIĆ, Stjepan. 1922. Dosad nepoznati hrvatskoglagolski prijevodi iz staročeškoga jezika. Slavia 6: 38-56, 285-300.

IVŠIĆ, Stjepan. 1927. Još o dosad nepoznatim glagolskim prijevodima sa staročeškoga jezika. Slavia 8: 40-63.

JAGIĆ, Vatroslav. 1913. Hrvatska glagolska književnost. U Povijest hrvatske književnosti, knj. 1, ur. Branko Vodnik, 9-60. Zagreb: Matica hrvatska,.

JAPUNDŽIĆ, Marko. 1995. Tragom hrvatskoga glagolizma. Zagreb: Provincijalat franjevaca trećoredaca, Kršćanska sadašnjost.

JURČEVIĆ, Ivan. 2002. Jezik hrvatskoglagoljskih tiskanih brevijara. Osijek: Sveučilište Josipa Jurja Strossmayera.

JURČEVIĆ, Ivan. 2005. Psalmi tiskani hrvatskom glagoljicom 1491. godine. Osijek: Sveučilište Josipa Jurja Strossmayera.

KAPETANIĆ, Niko, Mateo ŽAGAR. 2001. Najjužniji hrvatski glagoljski natpis. Anali Zavoda za povijesne znanosti Hrvatske akademije znanosti i umjetnosti u Dubrovniku 39: 9-48.

KAPETANOVIĆ, Amir, Dragica MALIĆ, Kristina ŠTRKALJ DESPOT. 2010. Hrvatsko srednjovjekovno pjesništvo. Zagreb: Institut za hrvatski jezik i jezikoslovlje.

KATIČIĆ, Radoslav. 1976. Zapisi s izvorišta. Slovo 25-26: 394-406.

KATIČIĆ, Radoslav. 1998. Litterarum studia. Književnost i naobrazba ranoga hrvatskog srednjovjekovlja. Zagreb: Matica hrvatska.

KATIČIĆ, Radoslav. 2013. Hrvatski jezik. Zagreb: Školska knjiga.

KOLUMBIĆ, Nikica. 1969. Hrvatska srednjovjekovna poezija i drama u svjetlu naše nauke o književnosti. Slovo 18-19: 251-265.

KOVAČIĆ, Slavko. 1993. Glagoljsko bogoslužje i glagoljaši na području srednje Dalmacije od XVI-XX. stoljeća. Kačić 25: 449-458.

KUNA, Herta. 1974. Hrestomatija starije bosanske književnosti. Knjiga I. Srednjovjekovna književnost i hrvatska književna tradicija. Sarajevo: Svjetlost.

KUŠTOVIĆ, Tanja. 2014. Prilozi u hrvatskoglagoljskim tekstovima. Zagreb: Matica hrvatska. 
LUKIĆ, Milica. 2009. Popularizacija ćirilometodske ideje u drugoj polovici 19. stoljeća na hrvatskome nacionalnom prostoru (Korpus ćirilometodskih književnih tekstova). Lingua Montenegrina 4: 85-124.

LUKIĆ, Milica. 2010. Ususret novijoj povijesti glagolizma. Lingua Montenegrina 5: 81-102.

MALIĆ, Dragica. 2002. Na izvorima hrvatskoga jezika. Zagreb: Matica hrvatska.

MALIĆ, Dragica. 2004. Skrivene veze hrvatske glagoljičke, ćiriličke i latiničke grafije. U Glagoljica i hrvatski glagolizam. Zbornik radova s međunarodnoga znanstvenog skupa povodom 100. obljetnice Staroslavenske akademije i 50. obljetnice Staroslavenskog instituta (Zagreb - Krk 2.-6. listopada 2002.), ur. Marija-Ana Dürrigl, Milan Mihaljević, Franjo Velčić, 549-560. Zagreb-Krk: Staroslavenski institut, Krčka biskupija.

MARGETIĆ, Lujo. 1997. O Bašćanskoj ploči. Krk: Povijesno društvo otoka Krka.

MIHALJEVIĆ, Milan. 1991. Generativna fonologija hrvatske redakcije crkvenoslavenskoga jezika [Biblioteka SOL]. Zagreb: Filozofski fakultet.

MIHALJEVIĆ, Milan. 2004. Deklinacija imenica u najstarijim hrvatskoglagoljskim fragmentima. U Glagoljica i hrvatski glagolizam. Zbornik radova s međunarodnoga znanstvenog skupa povodom 100. obljetnice Staroslavenske akademije i 50. obljetnice Staroslavenskog instituta (Zagreb - Krk 2.-6. listopada 2002.), ur. Marija-Ana Dürrigl, Milan Mihaljević, Franjo Velčić, 625-636. Zagreb-Krk: Staroslavenski institut, Krčka biskupija.

MIHALJEVIĆ, Milan. 2006. Sintaktička svojstva najstarijih hrvatskoglagoljskih tekstova. U Mnogokratnite prevodi v južnoslavjanskoto srednovekovie, ur. Lora Taseva, Roland Marti, Marija Jovčeva, 221-238. Sofija: Goreks Pres.

MIHALJEVIĆ, Milan. 2007. Leksik najstarijih hrvatskoglagoljskih fragmenata. Studia Slavica Hungarica 52: 263-272.

MIHALJEVIĆ, Milan, Johannes REINHART. 2005. The Croatian Redaction: Language and Literature. Incontri linguistici 28: 31-82.

MILČETIĆ, Ivan. 1911. Hrvatska glagoljska bibliografija. Starine 33: 1-536.

MOGUŠ, Milan. 2010. Kako pročitati Baščansku ploču?. Senjski zbornik 37: 33-44.

NAZOR, Anica. 1979. Zagreb - riznica glagoljice. Zagreb: Nacionalna i sveučilišna biblioteka.

NAZOR, Anica. 1984. Tiskana glagoljska knjiga od prvotiska Misala 1483. do Brozićeva brevijara 1561. Slovo 34: 7-16.

NAZOR, Anica. 1993. Hrvatskoglagoljske inkunabule: U povodu 500. obljetnice brevijara Blaža Baromića. Croatica 37-39: 229-257.

OSTOJIĆ, Ivan. 1963-1965. Benediktinci u Hrvatskoj I-III. Split: Benediktinski priorat Tkon.

PANTELIĆ, Marija Agnezija. 2013. Hrvatsko glagoljsko srednjovjekovlje. Prir. Petar Bašić. Zagreb: Kršćanska sadašnjost - Družba sestara milosrdnica svetog Vinka Paulskog u Zagrebu.

PETROVIĆ, Ivanka. 1972. Bogorodičina čudesa u Ivančićevu zborniku, hrvatskoglagoljskom spomeniku 14/15. stoljeća. Radovi Staroslavenskog instituta u Zagrebu 7: 123-210. 
PETROVIĆ, Ivanka. 1985. Franjo Rački - otac hrvatske Cyrillo-Methodiane. Zbornik Zavoda za povijesne znanosti JAZU 9: 47-99.

PETROVIĆ, Ivanka. 1988. Prvi susreti Hrvata s ćirilometodskim izvorištem svoje srednjovjekovne kulture. Slovo 38: 5-54.

PETROVIĆ, Ivanka. 2000. Hrvatska i europska hagiografija. U Hrvatska i Europa-kultura, znanost i umjetnost. Sv. II. Srednji vijek i renesansa (XIII - XVI. stoljeće), ur. Eduard Hercigonja, 321-347. Zagreb: Hrvatska akademija znanosti i umjetnosti, Školska knjiga.

REINHART, Johannes. 1990. Najstarije svjedočanstvo za utjecaj Vulgate na hrvatskoglagoljsku Bibliju. Slovo 39-40: 45-52.

REINHART, Johannes. 1997. Zwischenslavische Übersetzungen im Mittelalter. Wiener Slavistisches Jahrbuch 43: 189-203.

RITTIG, Svetozar. 1910. Povijest i pravo slovenštine u crkvenom bogoslužju, sa osobitim obzirom na Hrvatsku. Zagreb: C. Albrecht.

RUNJE, Petar. 1990. Prema izvorima [Novaja i vethaja 2]. Zagreb: Provincijalat franjevaca trećoredaca.

RUNJE, Petar. 1998. O knjigama hrvatskih glagoljaša. Zagreb: Provincijalat franjevaca trećoredaca, Kršćanska sadašnjost.

RUNJE, Petar. 2001. 22007. Tragom stare ličke povijesti. Ogulin: Ogranak Matice hrvatske Ogulin.

RUNJE, Petar. 2003. Školovanje glagoljaša. Ogulin: Ogranak Matice hrvatske Ogulin.

RUNJE, Petar. 2012. Prema izvorima II. Rasprave i članci o hrvatskim franjevcima trećoredcima glagoljašima. Ur. Tomislav Galović [Novaja i vethaja 9; Krčki zbornik 68, Posebno izdanje 61]. Krk-Zagreb: Povijesno društvo otoka Krka, Provincijalat franjevaca trećoredaca.

SAMBUNJAK, Slavomir. 2000. Jezik i stil hrvatskih glagoljskih prenja. Split: Književni krug.

SAMBUNJAK, Slavomir (prir.). 2001. Tkonski zbornik. Tkon: Općina Tkon.

STARČEVIĆ, Ante. 1852. Razvod istrianski od 1325. Arkiv za pověstnicu jugoslavensku II/2: 227-275.

SUČIĆ, Božo. 1995. Franjevci trećoreci glagoljaši i njihova baština u Zagrebačkoj nadbiskupiji. U Zagrebačka biskupija i Zagreb 1094. - 1994. Zbornik u čast kardinala Franje Kuharića - Novem saecula Dioecesis Zagrabiensis. Miscellanea in honorem Francisci cardinalis Kuharić, ur. Antun Škvorčević, 505-513. Zagreb: Nadbiskupija zagrebačka, Katolički bogoslovni fakultet Sveučilišta u Zagrebu.

ŠIMIĆ, Marinka. 2000. Jezik Muke po Mateju u hrvatskoglagoljskim misalima. Slovo 50: 5-117.

ŠTEFANIĆ, Vjekoslav. 1960. Glagoljski rukopisi otoka Krka. Zagreb: Jugoslavenska akademija znanosti i umjetnosti.

ŠTEFANIĆ, Vjekoslav. 1969-1970. Glagoljski rukopisi Jugoslavenske akademije I-II. Zagreb: Jugoslavenska akademija znanosti i umjetnosti.

ŠTEFANIĆ, Vjekoslav i sur. 1969. Hrvatska književnost srednjega vijeka od XII do XVI stoljeća [Pet stoljeća hrvatske književnosti 1]. Zagreb: Zora, Matica hrvatska. 
TANDARIĆ, Josip. 1993. Hrvatskoglagoljska liturgijska književnost. Zagreb: Provincijalat franjevaca trećoredaca, Kršćanska sadašnjost.

VAJS, Josip. 1948. Najstariji hrvatskoglagoljski misal. Zagreb: Jugoslavenska akademija znanosti i umjetnosti [Djela JAZU 38].

VAJS, Jozef. 1910. Nejstarši breviár charvatsko — hlaholský. Praha: Naklad. Král. společnosti nauk.

VINCE, Jasna. 1998. Neslaganje u padežu između direktnog objekta i njegove „najave“ u hrvatskom crkvenoslavenskom jeziku. U Prvi hrvatski slavistički kongres. Zbornik radova, ur. Stjepan Damjanović, 621-628. Zagreb: Hrvatsko filološko društvo.

VINCE, Jasna. 2004. Brojevi 1, 2, 11 i 12 u hrvatskom crkvenoslavenskom jeziku. U Glagoljica i hrvatski glagolizam. Zbornik radova s međunarodnoga znanstvenog skupa povodom 100. obljetnice Staroslavenske akademije i 50. obljetnice Staroslavenskog instituta (Zagreb-Krk 2.-6. listopada 2002.), ur. Marija-Ana Dürrigl, Milan Mihaljević, Franjo Velčić, 595-605. Zagreb-Krk: Staroslavenski institut, Krčka biskupija.

VRANA, Josip. 1955. Hrvatskoglagoljski blagdanar. Rad JAZU 285: 95-179.

ZARADIJA-KIŠ, Antonija. 1997. Knjiga o Jobu u hrvatskoglagoljskoj književnosti. Zagreb: Hrvatsko filološko društvo.

ZARADIJA-KIŠ, Antonija. 2001. Šimun Greblo i njegovo tumačenje Muke Kristove (1493.). Pazin-Buzet-Zagreb: „Juraj Dobrila“, Pazinski kolegij - klasična gimnazija, Katedra C̆akavskog sabora, Institut za etnologiju i folkloristiku.

ŽAGAR, Mateo. 1997. Kako je tkan tekst Bašćanske ploče?. Zagreb: Hrvatsko filološko društvo.

ŽAGAR, Mateo. 2007. Grafolingvistika srednjovjekovnih tekstova. Zagreb: Matica hrvatska.

ŽAGAR, Mateo. 2013. Uvod u glagoljsku paleografiju I (X. I XI. st.). Zagreb: Institut za hrvatski jezik i jezikoslovlje.

\section{A Millennium Old Croatian Glagolitic Culture and Its Foundations by Ss Cyril and Methodius}

The oldest Croatian Glagolitic texts come from the $11^{\text {th }}$ century. However, there are historical documents (especially papal letters) suggesting there must have been some as early as $10^{\text {th }}$ century too. Croatian philology (Eduard Hercigonja) styled the period up till the end of the $13^{\text {th }}$ century as ,time of fragments“ referring to the fact that no full codex, either liturgical or non-liturgical, has been preserved to us earlier than that. Fragments that did come down to us, are often just parts of large (in terms of size and number of pages) codices with which ,a very abundant material perished" (Stjepan Ivšić). In all the texts of that time, regardless of their functional direction, we find the same idiom - the Croatian version of the Old Church Slavonic tongue (Croatian Old Slavonic, Croatian 
Church Slavonic), which entitles us to the conclusion that this idiom served as a literary language.

The $14^{\text {th }}$ and $15^{\text {th }}$ centuries are referred to as the golden age of the Croatian Glagolitic culture. From that period we have some 30 complete breviaries, some 20 missals, 3 psalters as well as many fragments too. In the $13^{\text {th }}$ century, in 1248 to be more precise, pope Innocent IV allowed Philip, bishop of Senj, to be equal to his flock when performing acts of worship, i. e. he was permitted to celebrate mass and other rituals in the Croatian Old Slavonic tongue using books written in Glagolitic, and four years later (1252) he did the same for the Benedictines in Omišalj on the island of Krk. These papal privileges were clear signs of a more lenient pontifical policy towards the non-Latin liturgical languages and so this milder attitude influenced positively the development of the Croatian Glagolitic culture too. The permissions coincided with the emergence of plenary missals and books of hours the mobile Franciscan order was disseminating throughout Croatia too.

During this period the Croatian Church Slavonic is found mainly in liturgical texts, a special mixture of that language with Croatian idioms (mostly Čakavica, but also Kajkavica and, then finally, Štokavica) is found in texts of fiction and poetry, whereas the most pages written in the „pure vernacular“ occur in legal texts.

In the $16^{\text {th }}$ century the Glagolitic component of Croatian literacy was moving gradually from major culture centres toward the periphery leaving the main role to the Latin script used more and more widely to record Croatian language idioms. One should, however, by no means infer from that observation that the production of Glagolitic manuscripts and prints decreased as compared to the body of works from the ,golden age of Glagolitic writing“. It is rather a considerable amount of material we find from that period. So far the Croatian philology has studied only small portions of it, so the language of this monuments can today be discussed only in outlines. This considerable body of works was not being realised in a decreasing area and with diminished functions as sometimes maintained by our philological scholars saying the Glagolitic script was reduced to ecclesiastical use only. Such oppinions tend to overlook the large number of Glagolitic collective manuscripts from the $16^{\text {th }}$ century and the numerous Glagolitic texts of administrative, legal and other non-liturgical natures.

The end of the $16^{\text {th }}$ century is indeed the end of the natural development of the Croatian Glagolitic culture, because the $17^{\text {th }}$ and $18^{\text {th }}$ century brought with them a process of Russification/Ukrainianisation of Croatian Glagolitic books, which gave the Glagolitic culture the decisive leverage to move to the periphery of Croatian culture. The efforts of the Croatian followers of SS Cyril and Methodius in the $19^{\text {th }}$ century couldn't revive this ancient, but now abandoned tradition. 
The Croatian Glagolitic writing received impulses from multiple sources, influences of the West and East met together in it, especially in its earliest period. The work of SS Cyrill and Method was a major source for it, not only for the text tradition, but also and even more as a lasting inspiration and anchorage of the thought that God and man are best addressed by man in his mother tongue, that the love for one's own is not to be confused either with hostility towards the others and different or with unnecessary self-isolation. Born out of the work of the holy brothers of Thessalonica, the Croatian Glagolitic culture resisted the Latin idiom as the only legitimate literary and liturgical language, but from the $14^{\text {th }}$ century onwards the textual sources were mainly of Western origin (Glagolitic churchmen translated all the most important and most popular texts of the higher developed European literatures). Accordingly, their texts profess and prove them, despite the refusal of the Latin monopoly, to have been true sons of the Roman Church.

Keywords: Old Croatian Glagolitic Culture, Ss Cyril and Methodius, Slavic Studies, historiography, The Monastic III Order of Holy Father Francis

Ključne riječi: hrvatsko glagoljaštvo, sv. Ćiril i Metod, slavistika, historiografija, trećoreci

Stjepan Damjanović

Filozofski fakultet Sveučilišta u Zagrebu

Hr-10000 Zagreb, Ivana Lučića 3 stjepan.damjanovic@xnet.hr 


\section{FILOZOFSKI FAKULTET SVEUČILIŠTA U ZAGREBU \\ ZAVOD ZA HRVATSKU POVIJEST \\ INSTITUTE OF CROATIAN HISTORY \\ INSTITUT FÜR KROATISCHE GESCHICHTE}
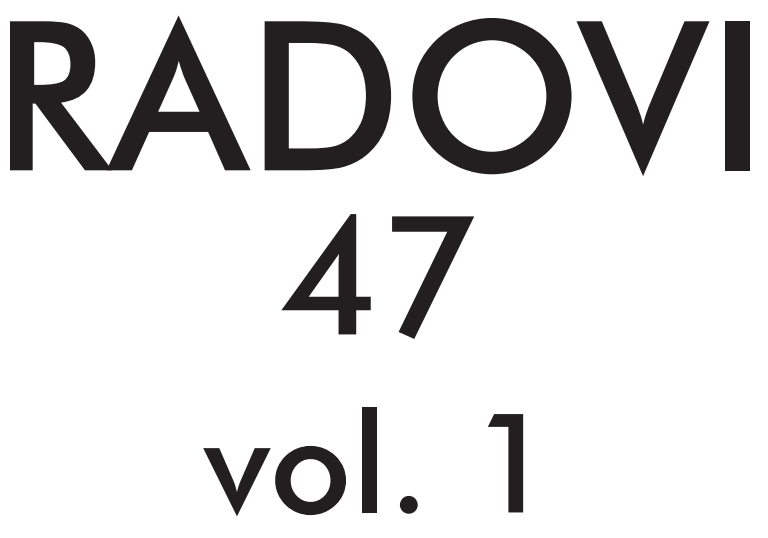

ZAVOD ZA HRVATSKU POVIJEST

FILOZOFSKOGA FAKULTETA SVEUČILIŠTA U ZAGREBU

\section{PF press \\ ZAGREB 2015.}




\title{
RADOVI ZAVODA ZA HRVATSKU POVIJEST FILOZOFSKOGA FAKULTETA SVEUČILIŠTA U ZAGREBU
}

\author{
Knjiga 47, vol. 1
}

\author{
Izdavač / Publisher \\ Zavod za hrvatsku povijest \\ Filozofskoga fakulteta Sveučilišta u Zagrebu \\ FF-press \\ Za izdavača / For Publisher \\ Vlatko Previšić \\ Glavni urednik / Editor-in-Chief \\ Hrvoje Gračanin \\ Izvršna urednica / Executive Editor \\ Inga Vilogorac Brčić \\ Uredništvo / Editorial Board
}

Bruna Kuntić-Makvić (stara povijest/ancient history), Zrinka Nikolić Jakus (srednji vijek/ medieval history), Hrvoje Petrić (rani novi vijek/early modern history), Željko Holjevac (moderna povijest/modern history), Tvrtko Jakovina (suvremena povijest/contemporary history),

Silvija Pisk (mikrohistorija i zavičajna povijest/microhistory and local history),

Zrinka Blažević (teorija i metodologija povijesti/theory and methodology of history)

Međunarodno uredničko vijeće / International Editorial Council

Denis Alimov (Sankt Peterburg), Živko Andrijašević (Nikšić), Csaba Békés (Budapest), Rajko Bratož (Ljubljana), Snježana Buzov (Columbus, Ohio), Svetlozar Eldarov (Sofija), Toni Filiposki (Skopje), Aleksandar Fotić (Beograd), Vladan Gavrilović (Novi Sad), Alojz Ivanišević (Wien),

Egidio Ivetić (Padova), Husnija Kamberović (Sarajevo), Karl Kaser (Graz),

Irina Ognyanova (Sofija), Géza Pálffy (Budapest), Ioan-Aurel Pop (Cluj),

Nade Proeva (Skopje), Alexios Savvides (Kalamata), Vlada Stanković (Beograd), Ludwig Steindorff (Kiel), Peter Štih (Ljubljana)

Izvršna urednica za tuzemnu i inozemnu razmjenu / Executive Editor for Publications Exchange Kristina Milković

Tajnik uredništva / Editorial Board Assistant

Dejan Zadro

Adresa uredništva/Editorial Board address

Zavod za hrvatsku povijest, Filozofski fakultet Zagreb, Ivana Lučića 3, HR-10 000, Zagreb

Tel. ++385 (0)1 6120 150, 6120 158, faks ++385 (0)1 6156879

Časopis izlazi jedanput godišnje / The Journal is published once a year

Časopis je u digitalnom obliku dostupan na / The Journal in digital form is accessible at Portal znanstvenih časopisa Republike Hrvatske „Hrčak“ http://hrcak.srce.hr/radovi-zhp

Financijska potpora za tisak časopisa / The Journal is published with the support by

Ministarstvo znanosti, obrazovanja i športa Republike Hrvatske

Časopis je indeksiran u sljedećim bazama / The Journal is indexed in the following databases:

Directory of Open Access Journals, EBSCO, SCOPUS, ERIH PLUS 
Naslovna stranica

Iva Mandić

Grafičko oblikovanje i računalni slog

Marko Maraković

Lektura

Samanta Paronić

Tisak

Web2tisak, Zagreb

Naklada

250 primjeraka

Časopis je u digitalnom obliku dostupan na Portalu znanstvenih časopisa Republike Hrvatske ,Hrčak“ http://hrcak.srce.hr/radovi-zhp

The Journal is accessible in digital form at the Hrcak - Portal of scientific journals of Croatia http://hrcak.srce.hr/radovi-zhp 


\section{RADOVI 47}

\section{vol. 1}

ZaVoda za hrVAtSku poviJest FILOZOFskoga fakulteta SVeuČILIŠTA u Zagrebu 


\title{
Tematski blok / Themed issue
}

\section{TREĆOREDSKA GLAGOLJAŠKA TRADICIJA U EUROPSKOM KONTEKSTU TERTIARY GLAGOLITIC TRADITION IN EUROPEAN CONTEXT}

\author{
Radovi međunarodnoga znanstvenog skupa \\ održanoga 27. i 28. IX. 2013. na Hrvatskom katoličkom sveučilištu u Zagrebu \\ u organizaciji \\ Provincije franjevaca trećoredaca glagoljaša u Zagrebu, Hrvatskoga katoličkog \\ sveučilišta u Zagrebu, Filozofskoga fakulteta Sveučilišta u Zagrebu - Odsjek za \\ povijest, Filozofskoga fakulteta Sveučilišta u Splitu - Odsjek za povijest, Instituta \\ za povijest umjetnosti u Zagrebu i Staroslavenskoga instituta u Zagrebu \\ Proceedings of the International Scientific Conference \\ held on 27th and 28th September 2013 at the Catholic University of Croatia in Zagreb \\ and organized by \\ the Province of the Glagolitic Friars of the Third Order Regular, Catholic University \\ of Croatia in Zagreb, Faculty of Humanities and Social Sciences of the University \\ of Zagreb - Department of History, Faculty of Humanities and Social Sciences of \\ the University of Split - Department of History, Institute of Art History, \\ and Old Church Slavonic Institute
}

Gosti urednici / Guest editors

\author{
Ivan BOTICA \\ Tomislav GALOVIĆ \\ Kristijan KUHAR
}

